\title{
Reviu Sistematik Penelitian Organizational Citizenship Behavior (OCB) di Indonesia
}

\section{Organizational Citizenship Behavior Research in Indonesia: A Systematic Review}

\author{
Novika Grasiaswaty \\ Fakultas Psikologi, Universitas YARSI
}

\begin{abstract}
Research about Western Organizational Citizenship Behavior had already gotten attention from industrial and social scientist and made them formulated some literature review and meta-analysis about this construct. Differ from OCB research in Indonesia, even gained same popularity, there is no literature review was conducted about this construct. This literature review was formulated from OCB research in the last 10 years (2009-2019) which is conducted in Indonesia. There are articles and result showed that OCB in Indonesia : (1) still focused in white collar respondents (2) most research using paper and pencil questionnaire and one source thus will lead to possible common method variance. There are some suggestions for future OCB research in Indonesia.
\end{abstract}

Keywords: OCB; Indonesia; literature review.

Abstrak. Penelitian mengenai Organizational Citizenship Behavior (OCB) telah berkembang pesat di Barat dan merumuskan beberapa reviu literatur maupun metaanalisis yang pada akhirnya membentuk konstruk ini menjadi lebih ajek dan menentukan arah penelitian selanjutnya. Berbeda dengan penelitian OCB di Indonesia, meskipun juga populer, tetapi kajian literatur mengenainya masih belum ditemui. Kajian literatur kali ini dilakukan pada artikel yang meneliti OCB di Indonesia pada rentang sepuluh tahun terakhir (2009-2019). Didapatkan beberapa artikel dan hasil dari reviu yang menunjukkan jika penelitian OCB di Indonesia : (1) Konstruk yang digunakan terfokus pada beberapa konstruk arus utama dan pada responden kerah putih serta (2) metode penelitian sebagian besar masih menggunakan paper and pencil questionnaire dan (3) sumber data didapat dari satu sumber primer untuk dua atau lebih variabel sehingga rentan dengan common method variance. Reviu diakhiri dengan usulan untuk penelitian mengenai OCB di Indonesia ke depannya.

Kata kunci: Indonesia; $\mathrm{OCB}$; reviu literatur 


\section{Pengantar}

Term organizational citizenship behavior (OCB) mulai diperkenalkan lebih dari tiga dekade yang lalu (Bateman \& Organ, 1983) dan konstruk ini menarik minat peneliti terutama peneliti di bidang ilmu organisasi sosial (Arthaud-Day et al., 2012; Bolino et al., 2015; Rotundo \& Sackett, 2002). Meta-analisis yang dilakukan oleh Podsakoff et al., (2000) mengemukakan jika selama rentang waktu 1983 hingga 1988, atau hanya lima tahun sejak term OCB muncul, 122 artikel ilmiah mengenainya telah dipublikasikan. Dalam situs pencarian ilmiah EBSCOhost, pengetikan dengan kata kunci "organizational citizenship behavior" menghasilkan 3711 artikel jurnal, mengindikasikan bagaimana populernya konstruk ini.

Tidak hanya di Barat, penelitian mengenai OCB juga marak di Indonesia. Salah satu penelitian awal di Indonesia mengenai konstruk ini dilakukan oleh Wijayanto \& Kismono (2004) yang mengungkapkan bagaimana konstruk ini timbul karena adanya job embeddedness dan dimediasi oleh rasa bertanggung jawab dari para suster di sebuah rumah sakit swasta di Indonesia. Penelitian tersebut kemudian diikuti oleh penelitianpenelitian selanjutnya pada sampel, jenis penelitian hingga anteseden yang beragam (Aini et al., 2014; Hapsari, 2009; Ramdhani et al., 2017; Susanto, 2015).

Meskipun telah banyak penelitian mengenai OCB di Indonesia, penelitian yang secara khusus mengulas penelitian-penelitian terdahulu dalam bentuk artikel reviu mengenai konstruk ini belum ditemukan. Padahal, artikel reviu dibutuhkan agar sebuah konstruk menjadi lebih ajek dan memiliki arah penelitian selanjutnya (Galvan \& Galvan, 2017). Dalam hal ini, diharapkan penelitian yang berkenaan dengan konstruk OCB di Indonesia dapat memiliki arah yang lebih jelas. Tulisan ini bertujuan untuk memberikan ulasan mengenai penelitian OCB di Indonesia pada rentang 10 tahun terakhir. Tulisan dimulai dari penjelasan mengenai konstruk dan sejarah $O C B$, metode pemilihan artikel, pembahasan mengenai usulan penelitian lanjutan mengenai OCB di Indonesia serta simpulan.

\section{Konstruk dan Sejarah Citizenship}

Awalnya, Bateman dan Organ (1983) mendefinisikan OCB sebagai semua tingkah laku individu di tempat kerja yang dapat melancarkan kinerja organisasi. Perilaku ini bisa berupa membantu rekan kerja dalam pekerjaannya, tidak mengeluhkan hal kecil dalam pekerjaan, serta menjaga aset organisasi. Landasan berpikir Bateman dan Organ (1983) ini sangat dipengaruhi oleh psikologi sosial, sehingga tidak heran beberapa aitem untuk mengukur OCB sangat erat dengan term psikologi sosial, misalnya altruism, compliance, serta cooperation. Sejalan dengan pendapat ini, Smith et al. (1983) mempertajam konstruk OCB itu sendiri dan memampatkan menjadi dua term, yaitu Altruism (tingkah laku seseorang yang secara langsung bertujuan menolong orang tertentu pada situasi yang saling berhadapan) dan general compliance (tingkah laku yang lebih didasari oleh conscientiousness individu, tidak ditujukan secara langsung pada orang lain tetapi dapat membantu secara tidak langsung ketika berada di dalam sistem). Organ (1997) kemudian 
memperbarui definisinya dan mengemukakan dimensi OCB menjadi helping, courtesy, dan counscientiousness. Sedikit berbeda dengan pendapat Organ et al. (1997) berpendapat jika secara empiris, konstruk altruism dan courtesy susah dibedakan oleh supervisor karena definisi yang sering tumpang tindih. Mereka menyarankan agar dalam konteks empiris dunia kerja, konstrak tersebut dapat dijadikan satu dengan helping behavior yang menjadikan konsep OCB terbagi jadi 3 dimensi, yaitu helping behavior, sportmanship dan civic virtue.

Pemahaman OCB yang juga mendapat perhatian dikemukakan oleh Williams dan Anderson (1991). Mereka melihat jika sebenarnya kepada siapa OCB ditujukan menjadi salah satu poin penting dalam memahami OCB itu sendiri, sehingga mereka membagi OCB menjadi dua yaitu OCB-I, atau perilaku OCB yang ditujukan kepada individu (bisa kepada rekan kerja atau atasan) serta OCB-O, yaitu perilaku OCB yang ditujukan kepada organisasi, misalnya menjaga aset organisasi dan kehadiran yang diatas rata-rata. Jika dicermati, Williams dan Anderson (1991) tidak mengubah esensi dari pemahaman OCB yang telah dikemukakan oleh peneliti sebelumnya. Mereka hanya membedakan jenis OCB yang nantinya perbedaan tersebut berimplikasi pada penelitian-penelitian selanjutnya.

Dari semua pemahaman mengenai OCB, ada beberapa garis besar yang semua ahli tampaknya saling sepakat mengenai $\mathrm{OCB}$, yaitu (1) perilaku ini di luar dari kewajiban seorang karyawan sehingga mestinya tidak diikutkan dalam penilaian performa kerja serta (2) jika dilakukan dalam jangka waktu lama atau banyak yang melakukan dapat meningkatkan efektivitas dari organisasi/perusahaan. Yang patut menjadi perhatian adalah OCB bukanlah bentuk positif dari counterproductive behavior. Kedua konstruk ini berbeda, bukan pada satu kontinum, meskipun keduanya merupakan bentuk extra role behavior (Podsakoff \& MacKenzie, 1997). Ketiadaan OCB tidak serta merta membuktikan adanya counterproductive behavior ataupun sebaliknya (Spector et al., 2010).

Reviu sistematik kali ini dimaksudkan untuk memberikan pemahaman lebih komprehensif mengenai penelitian OCB yang telah dilakukan di Indonesia. Reviu sistematik dilakukan dengan mengumpulkan artikel penelitian-penelitian yang telah dilakukan di Indonesia. Artikel penelitian tersebut kemudian dianalisis berdasarkan konstruk OCB yang dilakukan, metode penelitian serta anteseden yang dilakukan.

\section{Metode}

Pencarian data dilakukan melalui tiga buah database online journal yang dapat diakses oleh peneliti, yaitu: WorldCat, Portal Garuda Indonesia serta EBSCOhost dan ProQuest yang dilanggan oleh Ristekdikti. Kriteria inklusi dari pencarian ini adalah : (1) penelitian dilakukan mulai tahun 2009 hingga 2019; (2) meneliti konstruk "organizational citizenship behavior" ataupun "perilaku kewarganegaraan organisasi" sebagai dependent variable (3) masuk ke dalam jurnal nasional terakreditasi saat artikel tersebut terbit (Sinta 1 atau Sinta 2) ataupun jurnal internasional bereputasi (bukan skripsi, tesis ataupun prosiding). 
Sementara untuk kriteria eksklusi dari pencarian ini adalah : (1) penelitian kualitatif/reviu literatur/ psychometric review.

\section{Pembahasan}

\section{Hasil}

Berdasarkan hasil penelusuran, terdapat 17 artikel yang sesuai dengan kriteria inklusi maupun eksklusi. Secara umum, penelitian yang dilakukan di Indonesia mengenai OCB melibatkan pekerja di ranah kerah putih (white collar) dan metode yang digunakan dengan mengumpulkan data primer berupa kuesioner. Sementara itu, sebagian besar penelitian diterbitkan pada jurnal dengan latar belakang ekonomi dan bisnis, sementara sisanya diterbitkan pada jurnal psikologi maupun pendidikan. Hasil penelusuran dapat dilihat pada Tabel 1. Untuk memudahkan, pembahasan hasil dijadi dalam beberapa sub bagian tersendiri.

\section{Konstruk OCB yang Diteliti di Indonesia}

Jika dicermati konstruk organizational citizenship yang paling banyak diadopsi oleh peneliti Indonesia adalah milik Organ (1988) ataupun turunannya (Organ et al., 2006), baik yang diadaptasi secara langsung (Djati \& Adiwijaya, 2009; Fatdina, 2015; Karim, 2010; Prasetyawati \& Putra, 2016; Tjahjono et al., 2018) maupun yang secara tidak langsung (Rahmi \& Riyono, 2016; Ramdhani et al., 2017). Konstruk OCB ini terbagi menjadi lima dimensi, yaitu altruism, courtesy, conscientiousness, civic virtue dan sportmanship. Altruism mengacu pada sejauh apa seorang pegawai cukup 'baik hati' untuk membantu pegawai lainnya. Conscientiousness adalah dimensi yang menunjukkan keinginan pegawai dalam mengikuti aturan, tidak datang terlambat serta beristirahat tepat waktu. Sementara sportmanship merujuk pada kerelaan untuk mentoleransi hal-hal yang tidak ideal di tempat kerja. Dimensi selanjutnya, civic virtue adalah perilaku yang menunjukkan kebertanggungjawaban seseorang terhadap keberlangsungan organisasi dan courtesy mengarah pada perilaku individu yang bertujuan untuk menghindari masalah-masalah terkait pekerjaan dengan karyawan lain.

Konstruk OCB yang juga diminati oleh peneliti Indonesia adalah milik Williams dan Anderson (1991) yang digunakan oleh Ariani (2012), (Sahertian, 2010), serta Purba et al. (2015). William dan Anderson (1991) membagi OCB menjadi dua dimensi berdasarkan target tingkah laku OCB itu sendiri, yaitu OCB-I (individual) atau perilaku yang ditujukan pada individu dan OCB-O (organization) atau perilaku yang ditujukan pada Organisasi. Salah satu contoh OCB-I adalah membantu pekerjaan rekan kerja meskipun bukan tugasnya sementara OCB-O dapat terlihat dari sejauh mana seorang karyawan mengikuti aturan-aturan tidak tertulis dari organisasi tempatnya bekerja. Pembagian based on target perilaku ini juga dilakukan oleh McNeely dan Meglino (1994) serta Lee dan Allen (2002) yang juga digunakan oleh Amir dan Santoso (2019).

Meskipun lebih sedikit peneliti yang menggunakan pembagian OCB berdasarkan target tingkah laku, tetapi pemisahan dimensi ini memperkaya pemahaman mengenai penyebab OCB itu sendiri. Penelitian yang dilakukan Amir dan Santoso (2019) misalnya, 
mengungkapkan jika hasil yang berbeda untuk jenis OCB yang berbeda. Hanya dua dimensi kepemimpinan melayani (servant leadership) yang berperan terhadap OCB-I, yaitu standing back dan authenticity sementara pada OCB-O dua dimensi yang berperan adalah empowerment dan standing back. Hasil ini juga sejalan dengan penelitian yang dilakukan di Barat. Arthaud-Day et al. (2012) menemukan jika nilai personal yang berbeda memengaruhi dimensi OCB yang berbeda pula. Perbedaan anteseden antara keduanya menunjukkan bahwa meskipun dalam satu wadah besar citizenship, keduanya merupakan dimensi yang berbeda.

Seragamnya konstruk OCB yang diteliti oleh peneliti di Indonesia memberikan beberapa ruang untuk pengembangan konstruk ini terutama OCB dalam bentuk yang berbeda. Salah satu pemahaman mengenai OCB yang sedikit berbeda dikemukakan oleh Van Dyne dan LePine (1998). Pengkategorisasian OCB yang dikemukakan oleh Van Dyne dan LePine (1998) menggunakan filosofi politik dan membentuk pengkategorisasian OCB menjadi dua tipe, yaitu berdasarkan keaktifan tingkah laku (promotif vs prohibitif) dan berdasarkan tujuan dari tingkah laku tersebut (afiliasi vs challenging). Dari dua tipologi tersebut, Van Dyne dan LePine (1998) membagi jenis-jenis tingkah laku OCB menjadi empat jenis, perilaku menolong (promotif-afiliasi), bersuara/mengemukakan pendapat (promosi-challenging), stewardship (prohibisi-afiliasi) serta whistle-blowing (prohibisichallenging). Salah satu poin menarik yang membedakan konstruk OCB Van Dyne dan LePine (1998) dengan OCB milik Organ (1988) adalah bagi Van Dyne \& LePine perilaku OCB bisa jadi merusak hubungan baik antar karyawan, misalnya ketika memberikan pendapat yang membangun tetapi merusak harmoni kelompok (contoh untuk bersuara) atau melaporkan adanya kecurangan yang dilakukan karyawan lain meskipun tetap dalam koridor 'demi kebaikan organisasi secara keseluruhan. Di sisi lain, Organ (1988) mengkotakkan OCB sebagai perilaku yang sejalan dengan efisiensi dan efektivitas organisasi dan menekankan harmoni kelompok. Penelitian lanjutan mengenai OCB dalam bentuk yang berbeda sangat disarankan agar pemahaman lebih jauh mengenai konstruk ini di Indonesia dapat dicapai. 
GRASIASWATY \| REVIU SISTEMATIK

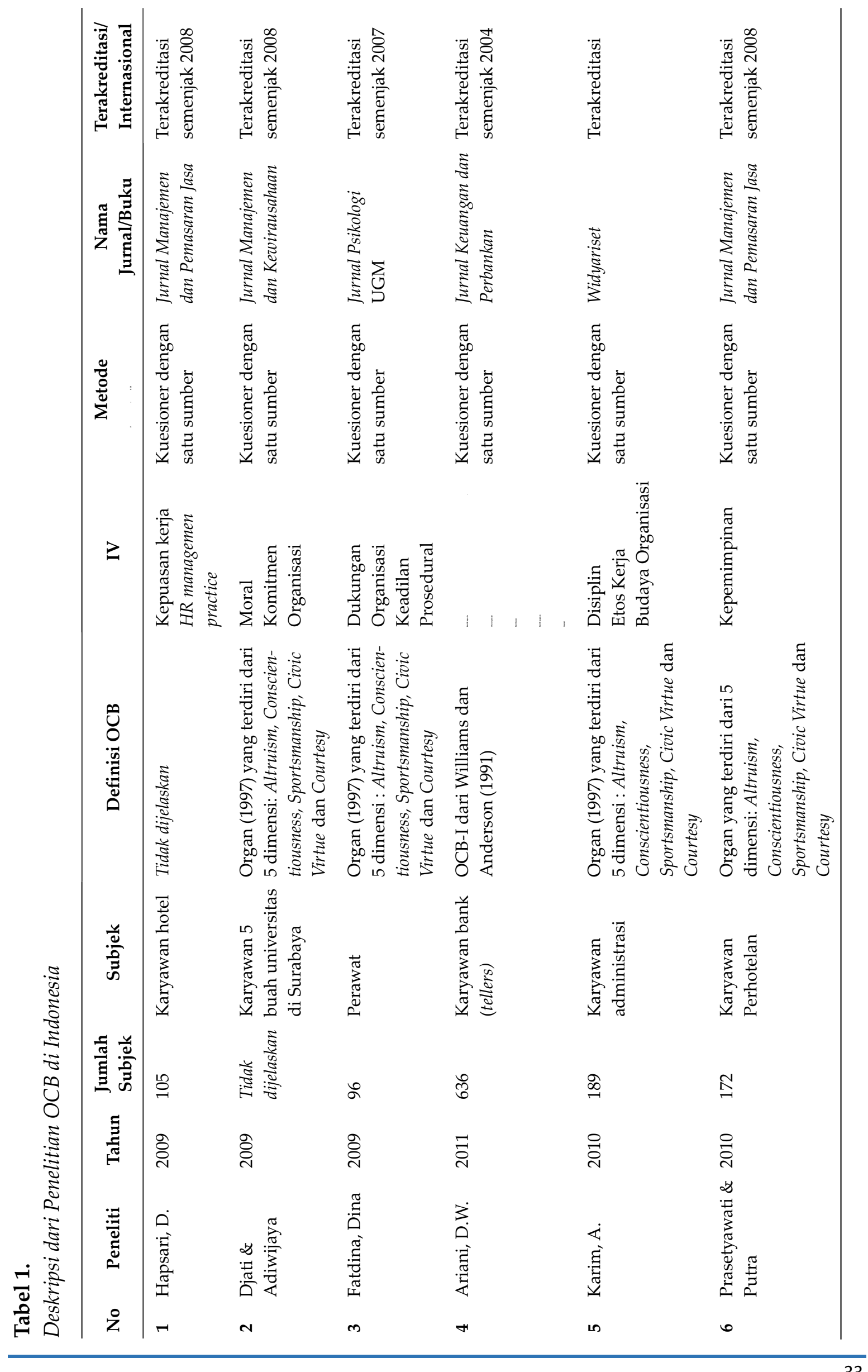


GRASIASWATY \| REVIU SISTEMATIK

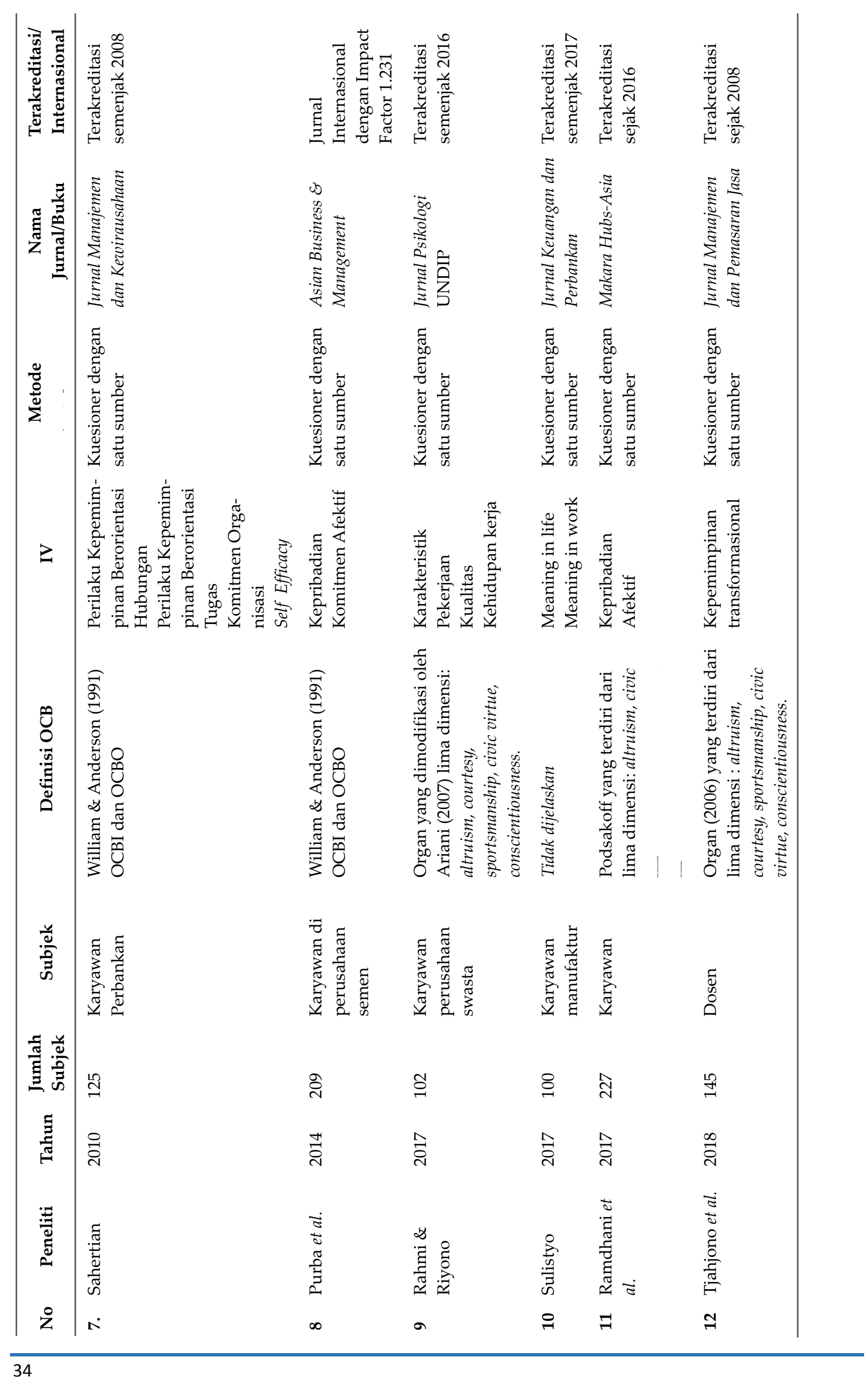


GRASIASWATY \| REVIU SISTEMATIK

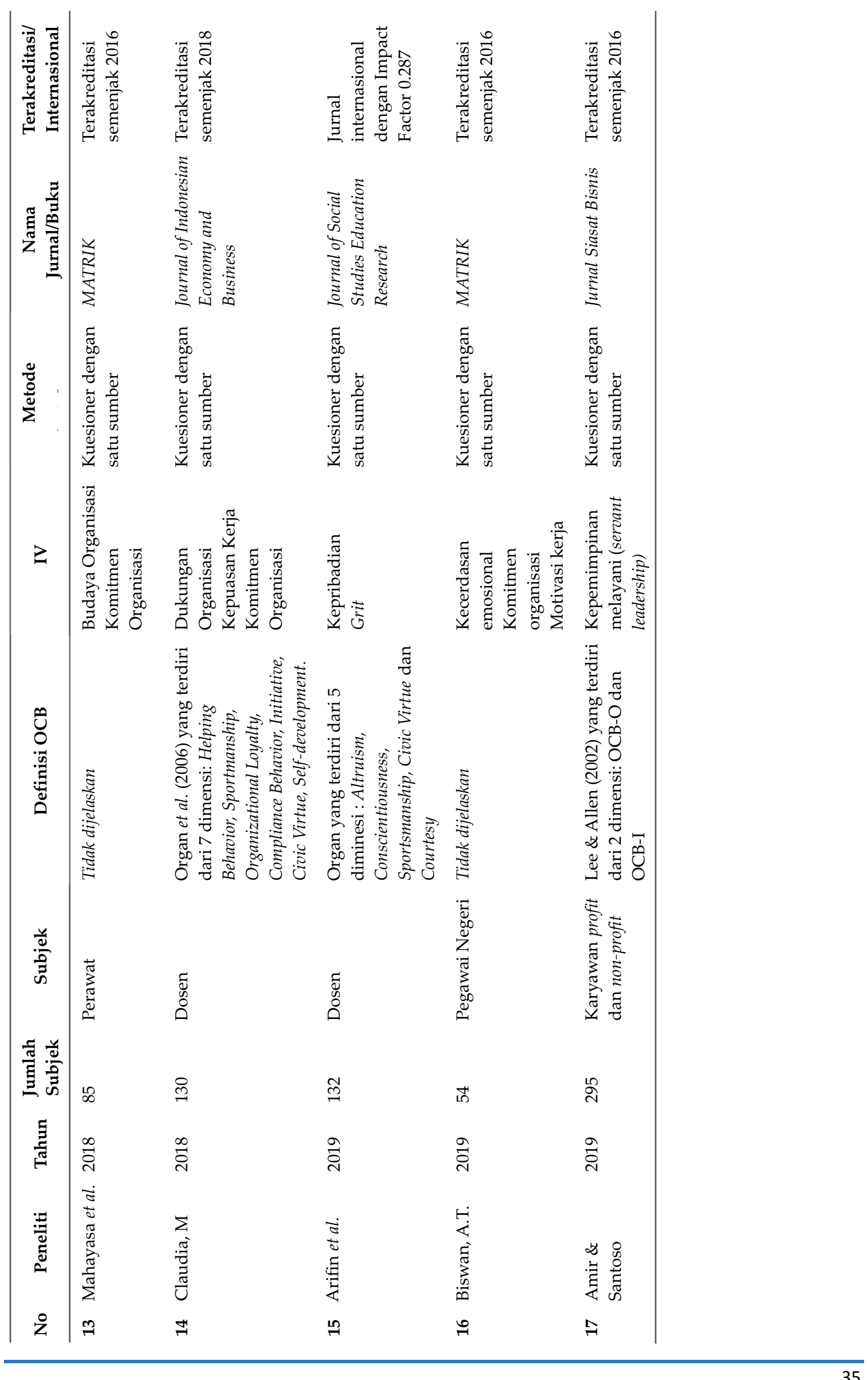




\section{Responden Penelitian OCB di Indonesia}

Dari data di Tabel 1, terlihat jika yang menjadi partisipan dalam penelitian OCB di Indonesia semua merupakan karyawan kerah putih, atau tenaga kerja yang memiliki kompetensi ataupun pendidikan khusus untuk bekerja (Maron et al., 2016). Sebagian besar responden adalah karyawan di perusahaan swasta, diikuti oleh pegawai negeri sipil, dosen serta guru. Padahal, perbedaan pengalaman kerja yang dialami oleh pekerja kerah putih dengan kerah biru dapat menyebabkan perilaku kerja yang berbeda pula (Berg et al., 2010).

Perbedaan kuantitas penelitian pada pekerja kerah putih dan kerah biru pada penelitian OCB tidak hanya ditemui di Indonesia. Reviu literatur yang dilakukan oleh (Podsakoff et al., 2000) mengungkapkan jika sebagian besar penelitian OCB di Amerika Serikat juga berpusat pada responden kerah putih, terutama tentara, organisasi profit maupun nonprofit, profesional serta mahasiswa.

Perbedaan tersebut mengindikasikan, meskipun konstruk ini cukup populer, tetapi penelitian mengenainya terfokus pada partisipan tertentu, yaitu kerah putih. Ketimpangan ini menyisakan beberapa gap dalam penelitian OCB. Pertama, alat ukur yang digunakan merefleksikan OCB dalam karyawan kerah putih yang bisa jadi aitemnya tidak relevan bagi responden kerah biru. Nielsen dan Abildgaard (2012) dalam sebuah inspeksi mengenai sebuah alat ukur di bidang psikologi industri, mengungkapkan jika beberapa aitem yang mengacu pada kegiatan kerja yang berkaitan dengan kognitif ataupun yang kata-katanya kurang dapat dipahami oleh pekerja kelas bawah akan menimbulkan hasil yang berbeda.

Kedua, korelasi atau keterkaitan antar konstruk dengan OCB sendiri bisa jadi berbeda antara kerah putih dan kerah biru. Beberapa penelitian pada konstruk kerja lain menunjukkan hasil yang berbeda pada kedua jenis pekerjaan ini (Berg et al., 2010). Perbedaan ini bisa jadi juga terjadi pada konstruk OCB, yang sayangnya belum terlihat karena tidak banyak penelitian yang mengkhususkan pada pekerja kerah biru.

\section{Anteseden OCB di Indonesia}

Dari beberapa penelitian mengenai OCB di Indonesia yang ada di Tabel. 1, prediktor atau anteseden ini dapat dikategorikan menjadi dua kelompok yaitu prediktor yang berasal dari perbedaan individual serta konteks di luar individu (kelompok atau organisasi). Faktor perbedaan individual (individual differences) dapat dilihat dari beberapa aspek yaitu traits/disposisi, motif, sikap kerja, nilai, dan afeksi. Menarik jika terlihat, penelitian mengenai OCB yang masuk ke dalam jurnal ekonomi ataupun manajemen lebih menitikberatkan pada aspek di luar individu sementara jurnal-jurnal berbasis psikologi memfokuskan pada aspek internal dari seorang karyawan.

Aspek internal yang meneliti peranan kepribadian dilakukan oleh Purba et al. (2014) dan Ramdhani et al. (2017). Hasil tersebut mengungkapkan trait extraversion dan emotional stability yang berperan terhadap OCB pada karyawan di Indonesia. Kepribadian yang berkaitan dengan emosi, yaitu kepribadian afektif, juga diketahui berperan positif 
terhadap OCB di karyawan Indonesia (Ramdhani et al., 2017). Hal ini berbeda dengan penelitian di Barat yang menunjukkan beberapa trait berbeda yang berperan dalam OCB. Conscientiousness adalah salah satu trait yang menunjukkan hubungan yang konsisten meskipun hubungannya tidak cukup kuat dengan OCB (Konovsky \& Organ, 1996; Organ \& Ryan, 1995). Beberapa penelitian lain menunjukkan justru trait seperti conscientiousness ataupun trait orientasi kepada orang lain tidak menjadi prediktor langsung, tetapi menguatkan hubungan antara sikap seseorang dengan OCB (Korsgaard et al., 2010; Lester et al., 2008). Perbedaan hasil ini dapat menjadi salah satu landasan untuk penelitian lanjutan.

Aspek internal lain yang banyak diteliti berkaitan dengan sikap kerja. Kepuasan kerja dan komitmen organisasi adalah sikap kerja yang secara konsisten hasilnya positif signifikan terhadap OCB, baik pada penelitian di Indonesia (Biswan, 2019; Djati \& Adiwijaya, 2009; Hapsari, 2009; Mahayasa et al., 2018; Purba et al., 2015; Sahertian, 2010), maupun di negara lain (Guzman \& Espejo, 2015; Lester et al., 2008; Williams \& Anderson, 1991). Sehingga, bisa disimpulkan jika keterkaitan antara kepuasan kerja dan komitmen organisasi terhadap OCB tidak dipengaruhi negara tempat responden itu tinggal.

Tidak hanya faktor di dalam diri manusia, faktor luar atau kontekstual juga disinyalir menjadi salah satu prediktor OCB. Faktor kontekstual yang menjadi ketertarikan para peneliti mulai mengarah pada konteks kelompok serta atribut terkait kelompok ataupun organisasi. Di Indonesia, penelitian mengenai aspek kontekstual terpusat pada hubungan karyawan dengan supervisor langsung dan kepemimpinan (Amir \& Santoso, 2019; Prasetyawati \& Putra, 2016; Sahertian, 2010; Tjahjono et al., 2018) ataupun aspek organisasional misalnya persepsi dukungan organisasi (Claudia, 2018; Fatdina, 2015) ataupun budaya organisasi (Karim, 2010; Mahayasa et al., 2018). Hasil penelitian tersebut sejalan dengan beberapa penelitian di Barat atau negara lainnya yang menunjukkan peran positif signifikan konstruk-konstruk tersebut terhadap OCB (Bowler \& Brass, 2006; Chan \& Mak, 2012; Chiaburu \& Byrne, 2009; Farmer et al., 2015; Walumbwa et al., 2010).

\section{Metode Penelitian yang Digunakan untuk Meneliti OCB di Indonesia}

Salah satu temuan menarik adalah semua penelitian menggunakan data primer atau kuesioner untuk mengambil data OCB dan sebagian besar menggunakan lapor diri. Padahal, penggunaan metode lapor diri diketahui memiliki banyak celah dan memungkinkan terjadinya common method variance (Podsakoff et al., 2003). Common method variance diketahui jika sumber data penelitian berasal dari satu sumber, misalnya untuk kuesioner lapor diri yang mengukur semua variabel baik variabel terikat maupun variabel bebas. Meskipun Spector (2006) menunjukkan bahwa pengambilan data dari satu sumber dalam penelitian organisasi dapat diantisipasi dengan teknik analisis lanjutan yang tepat, tetapi hanya penelitian Purba et al. (2015) yang menunjukkan analisis data lanjutan untuk menunjukkan data mereka terbebas dari kemungkinan common method variance. Hal ini tidak ditemukan pada penelitian lain mengenai OCB di Indonesia. Padahal, berdasarkan meta-analisis yang dilakukan oleh Podsakoff et al. (2000), OCB 
merupakan salah satu konstruk dengan kecenderungan social desirability yang tinggi sehingga sangat rentan bias karena menggunakan sumber yang sama. Penelitian lanjutan di Indonesia mengenai OCB dapat mulai memperhatikan isu ini sehingga hasil penelitian dapat lebih dipertanggungjawabkan.

\section{Penutup}

Dari pemaparan di atas, ada beberapa poin yang dapat dijadikan masukan untuk penelitian mengenai OCB di Indonesia. Pertama, konstruk OCB yang digunakan masih mayoritas menggunakan konsep yang dikemukakan oleh Organ (2002; 2006). Sementara, konstruk OCB yang dikemukakan oleh William dan Anderson (1991) masih belum terlalu populer bagi peneliti di Indonesia. Selain itu, beberapa peneliti juga telah mengemukakan OCB-based company, atau konstruk OCB yang menyesuaikan dengan value ataupun karakteristik perusahaan. Penelitian yang dilakukan oleh Dekas et al. (2013) mengungkapkan jika pada Google, Inc. diperlukan perumusan OCB yang lebih cocok dengan karakteristik perusahaan. Hal ini membuat OCB yang dirumuskan Dekas et al. (2013) memasukkan voice dan helping behavior dalam OCB versi mereka, padahal keduanya selama ini dianggap konstruk yang berbeda dengan OCB meskipun dalam satu payung besar contextual performance.

Implikasinya untuk penelitian OCB bagi perusahaan-perusahaan di Indonesia perlu melakukan pengkajian ulang mengenai OCB yang khusus untuk untuk beberapa perusahaan ataupun karakteristik pekerjaan tertentu. Menolong pasien misalnya bukan bentuk OCB bagi seorang perawat, tetapi adalah kewajiban. Sementara melakukan pekerjaan di luar birokrasi bagi seorang Aparatur Sipil Negara (ASN) bisa jadi melanggar OCB meskipun dimaksudkan untuk efisiensi.

Hal lain yang juga perlu dipahami jika melakukan penelitian lanjutan di Indonesia adalah memahami budaya Indonesia. Mangundjaya (2013) mengungkapkan jika karyawan di Indonesia memiliki nilai kolektivis yang tinggi dan menempatkan senioritas yang tinggi. Schwartz (2017) juga mengungkapkan bagaimana Indonesia memiliki kecenderungan untuk terikat dengan kelompoknya, sehingga akan sangat menghindari hal-hal yang mengganggu harmoni kelompok. Implikasinya adalah, alat ukur dengan bentuk-bentuk OCB yang sejatinya dapat mengganggu harmoni kelompok ini (contohnya voice atau taking charge dari Morrison \& Phelps, 1999) harus diadaptasi dengan lebih berhati-hati.

Kedua, penelitian OCB di Indonesia masih berpusat pada responden karyawan kerah putih, sehingga pemahaman keterkaitan antar konstruk OCB dengan konstruk lain tidak dapat divalidasi pada karyawan kerah biru. Eksplorasi pada jenis pekerjaan lain, misalnya kerah biru ataupun pekerjaan lain yang memiliki karakteristik yang berbeda dengan pekerja kantoran, misalnya precarious employee ataupun para buruh yang tidak memiliki job insecurity seperti karyawan kerah putih.

Ketiga, penelitian aspek internal, dalam hal ini kepribadian, masih menunjukkan hasil yang berbeda antara penelitian di Indonesia maupun di Barat. Hasil yang masih 
belum ajek ini dapat menjadi salah satu alasan untuk penelitian lanjutan di Indonesia terutama untuk mengeksplorasi apakah ada konstruk lain yang menjadi moderator antara kepribadian dan OCB. Salah satu hal yang patut menjadi catatan adalah penelitian kepribadian selama ini dilakukan dengan menggunakan konstruk dan alat ukur yang dirumuskan dari masyarakat Barat. Sementara, Hofstede dan McCrae (2004) mengungkapkan bagaimana kultur sebuah negara mempengaruhi kepribadian seseorang. Dari pemaparan tersebut, dapat diambil kesimpulan jika pemahaman penelitian yang menyangkut kepribadian di Indonesia haruslah melibatkan pembahasan mengenai kultur negara Indonesia pula.

Terakhir, meskipun sudah banyak dilakukan, tetapi metode penelitian yang dilakukan mayoritas menggunakan sumber tunggal yang dapat meningkatkan terjadinya common method bias (Podsakoff et al., 2003). Selain itu, konstruk OCB yang bersifat tinggi social desirability dapat membuat konstruk ini sangat rentan bias terutama jika dilakukan dengan lapor diri. Penelitian lanjutan akan lebih baik jika memperhatikan metode pengukuran dalam pengambilan data OCB itu sendiri, misalnya menggunakan teknik statistik yang tepat untuk mengecek terlebih dahulu mengenai ada tidaknya bias ini (Spector, 2006), misalnya dengan menggunakan Harman's single factor test ataupun memecah kuesioner menjadi beberapa lembar atau dalam waktu yang berbeda berdasarkan rekomendasi Podsakof et al. (2003).

\section{Ucapan Terima Kasih}

Penulis mengucapkan terima kasih kepada rekan-rekan Fakultas Psikologi Universitas YARSI yang telah mendorong penulis untuk menyelesaikan tulisan ini.

\section{Pendanaan}

Penelitian ini didanai oleh dana pribadi penulis sendiri.

\section{Pernyataan Konflik Kepentingan}

Penulis menyatakan tidak ada konflik kepentingan selama penyusunan manuskrip ini.

Orcid ID

Novika Grasiaswaty https://orcid.org/0000-0003-3519-7483

\section{Daftar Pustaka}

Aini, F. A., Hardjajani, T., \& Priyatama, A. N. (2014). Hubungan antara kualitas interaksi atasan-bawahan dan dan quality of work life dengan organizational citizenship behavior karyawan PT. Air Mancur Palur Karanganyar . Wacana Jurnal Psikologi, $6(11), 55-72$. 
Amir, D. A., \& Santoso, C. B. (2019). Examining a servant leadership construct and its influence on organizational citizenship behavior, Jurnal Siasat Bisnis, 23(1), 37-49. https://doi.org/10.20885/jsb.vol23.iss1.art4

Ariani, D. W. (2012). Leader-member exchanges as a mediator of the effect of job satisfaction on affective organizational commitment: An empirical test. International Journal of Management, 29(1), 46-56.

Arifin, M., Herri, Amali, H., Elfindri, Puteri, H. E. (2019). Personality, grit and organizational citizenship behavior at vocational higher education: The mediating role of job involvement. Journal of Social Studies Education Research, 10(2), 168-187.

Arthaud-Day, M. L., Rode, J. C., \& Turnley, W. H. (2012). Direct and contextual effects of individual values on organizational citizenship behavior in teams. Journal of Applied Psychology, 97(4), 792-807. https://doi.org/10.1037/a0027352

Bateman, T. S., \& Organ, D. W. (1983). Job satisfaction and the good soldier: The relationship between affect and employee "Citizenship." The Academy of Management Journal, 26(4), 587-595.

Berg, J. M., Wrzesniewski, A., \& Dutton, J. E. (2010). Perceiving and responding to challenges in job crafting at different ranks: When proactivity requires adaptivity. Journal of Organizational Behavior, 31(2-3), 158-186. https://doi.org/10.1002/job.645

Biswan, A. T. (2019). Peran mediasi motivasi kerja pada pengaruh kecerdasan emosional dan komitmen organisasi terhadap organizational citizenship behavior pegawai pemerintah. Matrik: Jurnal Manajemen, Strategi Bisnis dan Kewirausahaan, 13(2), 204. https://doi.org/10.24843/matrik:jmbk.2019.v13.i02.p08

Bolino, M. C., Hsiung, H.-H., Harvey, J., \& LePine, J. A. (2015). “Well, I'm tired of tryin'!" Organizational citizenship behavior and citizenship fatigue. Journal of Applied Psychology, 100(1), 56-74. https://doi.org/10.1037/a0037583

Bowler, W. M., \& Brass, D. J. (2006). Relational correlates of interpersonal citizenship behavior: A social network perspective. Journal of Applied Psychology, 91(1), 70-82. https://doi.org/10.1037/0021-9010.91.1.70

Chan, S. C. H., \& Mak, W. M. (2012). Benevolent leadership and follower performance: The mediating role of leader-member exchange (LMX). Asia Pacific Journal of Management, 29(2), 285-301. https://doi.org/10.1007/s10490-011-9275-3

Chiaburu, D. S., \& Byrne, Z. S. (2009). Predicting OCB role definitions: Exchanges with the organization and psychological attachment. Journal of Business and Psychology, 24(2), 1-14. https://doi.org/10.1007/s10869-009-9100-x

Claudia, M. (2018). The influence of perceived organizational support, job satisfaction and organizational commitment toward organizational citizenship behavior. Journal of Indonesian Economy and Business, 33(1), 23-45.

Dekas, K. H., Bauer, T. N., Welle, B., Kurkoski, J., \& Sullivan, S. (2013). Organizational citizenship behavior, version 2.0: A review and qualitative investigation of ocbs for knowledge workers at google and beyond. Academy of Management Perspectives, 27(3), 219-237. https://doi.org/10.5465/amp.2011.0097 
Djati, S. P., \& Adiwijaya, M. (2009). The Influence of the morale and the commitment of administration staff towards the organizational citizenship behavior and its impact towards service quality performance at private universities in Surabaya-Indonesia. Jurnal Manajemen dan Wirausaha, 11(1), 20-30.

Farmer, S. M., Frank Barton, W., Van Dyne, L., \& Kamdar, D. (2015). The contextualized self: How team-member exchange leads to coworker identification and helping OCB. Journal of Applied Psychology, 100(2), 583-595. https://doi.org/10.1037/a0037660

Fatdina, F. (2015). Peran dukungan organisasi yang dirasakan karyawan sebagai mediator pengaruh keadialan prosedural terhadap perilaku kewarganegaraan organisasi. Jurnal Psikologi, 36(1), 1 - 17.

Galvan, J. L., \& Galvan, M. C. (2017). Writing literature reviews: A guide for students of the social and behavioral sciences (Edisi ketujuh). Routledge.

Guzman, F. A., \& Espejo, A. (2015). Dispositional and situational differences in motives to engage in citizenship behavior. Journal of Business Research, 68(2), 208-215. https://doi.org/10.1016/j.jbusres.2014.09.029

Hapsari, D. (2009). Peranan organizational citizenship behavior dalam memediasi pengaruh job satisfaction dan human resources management practices terhadap service quality pada sebuah hotel bintang lima di Jakarta Pusat. Jurnal Manajemen dan Pemasaran Jasa. 2(1), 36-50. https://doi.org/10.25105/impj.v2i1.530

Hofstede, G., \& McCrae, R. R. (2004). Personality and culture revisited: Linking traits and dimensions of culture. Cross-Cultural Research, 38(1), 52-88. https://doi.org/10.1177/1069397103259443

Karim, A. (2010). Pengaruh disiplin, etos kerja, dan budaya organisasi terhadap organizational citizenship behavior pegawai administrator pelabuhan Tanjung Priok. Widyariset, 13(1), 21-30.

Konovsky, M. A., \& Organ, D. W. (1996). Dispositional and contextual determinants of organizational citizenship behavior. Journal of Organizational Behavior, 17(3), 253-266. https://doi.org/10.1002/(SICI)1099-1379(199605)17:3<253::AID-JOB747>3.0.CO;2-Q

Korsgaard, M. A., Meglino, B. M., Lester, S. W., \& Jeong, S. S. (2010). Paying you back or paying me forward: Understanding rewarded and unrewarded organizational citizenship behavior. Journal of Applied Psychology, 95(2), 277-290. https://doi.org/10.1037/a0018137

Lee, K., \& Allen, N. J. (2002). Organizational citizenship behavior and workplace deviance: the role of affect and cognitions. The Journal of Applied Psychology, 87(1), 131-142. https://doi.org/10.1037/0021-9010.87.1.131

Lester, S. W., Meglino, B. M., \& Korsgaard, M. A. (2008). The role of other orientation in organizational citizenship behavior. Journal of Organizational Behavior, 29(1), 829-841. https://doi.org/10.1002/job.504

Mahayasa, I. G. A., Sintaasih, D. K., \& Putra, M. S. (2018). Pengaruh kepuasan kerja dan budaya organisasi terhadap komitmen organisasional dan organizational citizenship behavior perawat. Matrik: Jurnal Manajemen, Strategi Bisnis dan Kewirausahaan, 12(1), 73. https://doi.org/10.24843/MATRIK:JMBK.2018.v12.i01.p08 
Mangundjaya, W. L. H. (2013). Is there cultural change in the national cultures of Indonesia? Dalam Y. Kashima, E. S. Kashima, \& R. Beatson (Eds.), Steering the cultural dynamics: Selected papers from the 2010 Congress of the International Association for Cross-Cultural Psychology. https://scholarworks.gvsu.edu/iaccp papers/105/

Maron, J., Kraus, L., Pogarell, O., Gomes De Matos, E., \& Piontek, D. (2016). Occupational inequalities in psychoactive substance use: A question of conceptualization? Addiction Research and Theory, 24(3), 186-198. https://doi.org/10.3109/16066359.2015.1093122

McNeely, B. L., \& Meglino, B. M. (1994). The role of dispositional and situational antecedents in prosocial organizational behavior: An examination of the intended beneficiaries of prosocial behavior. Journal of Applied Psychology, 79(6), 836-844. https://doi.org/10.1037/0021-9010.79.6.836

Morrison, E. W., \& Phelps, C. C. (1999). Taking charge at work: Extrarole efforts to initiate workplace change. Academy of Management Journal, 42(4), 403-419. https://doi.org/10.2307/257011

Nielsen, K., \& Abildgaard, J. S. (2012). The development and validation of a job crafting measure for use with blue-collar workers. Work and Stress, 26(4), 365-384. https://doi.org/10.1080/02678373.2012.733543

Organ, D. W. (1988). Organizational citizenship behavior: The good soldier syndrome. Lexington Books/D. C. Heath and Com.

Organ, D. W. (1997). Organizational citizenship behavior: It's construct clean-up time. Human Performance, 10(2), 99-109. https://doi.org/10.1207/s15327043hup1002 2

Organ, D. W., Podsakoff, P. M., \& MacKenzie, S. B. (2006). Organization citizenship behavior: Its nature, antecedents, and consequences. Sage Publications.

Organ, D. W., \& Ryan, K. (1995). A meta-analytic review of attitudinal and dispositional predictors of organizational citizenship behavior. Personnel Psychology, 48(4), 775802. https://doi.org/10.1111/j.1744-6570.1995.tb01781.x

Podsakoff, P. M., \& MacKenzie, S. B. (1997). Impact of organizational citizenship behavior on organizational performance: A review and suggestion for future research. Human Performance, 10(2), 133-151. https://doi.org/10.1207/s15327043hup1002 5

Podsakoff, P. M., MacKenzie, S. B., Lee, J. Y., \& Podsakoff, N. P. (2003). Common method biases in behavioral research: A critical review of the literature and recommended remedies. Journal of Applied Psychology, 88(5), 879-903. https://doi.org/10.1037/0021$\underline{9010.88 .5 .879}$

Podsakoff, P. M., MacKenzie, S. B., Paine, J. B., \& Bachrach, D. G. (2000). Organizational citizenship behaviors: A critical review of the theroetical and empirical literature and suggestions for future research. Journal of Management, 26(3), 513-563. https://doi.org/10.1177/014920630002600307

Prasetyawati, D., \& W. Gunawan Putra, A. (2016). Efek nilai kerja, otonomi, dan work setting terhadap kepemimpinan dan perilaku organisasi pada industri jasa perhotelan. Jurnal Manajemen dan Pemasaran Jasa, 3(1), 1-12. https://doi.org/10.25105/jmpj.v3i1.477 
Purba, D. E., Oostrom, J. K., Van Der Molen, H. T., \& Born, M. P. (2015). Personality and organizational citizenship behavior in Indonesia: The mediating effect of affective commitment. Asian Business and Management, 14(2), 147-170. https://doi.org/10.1057/abm.2014.20

Rahmi, F., \& Riyono, B. (2016). Pengaruh karakteristik pekerjaan terhadap perilaku kewargaan organisasi dengan mediator nilai-nilai kualitas kehidupan kerja. Jurnal Psikologi, 15(1), 64-76. https://doi.org/10.14710/jpu.15.1.64-76

Ramdhani, N., Ancok, D., \& Adrianson, L. (2017). The importance of positive affect: The role of affective personality in predicting organizational citizenship behavior. Makara Human Behavior Studies in Asia, 21(2), 62-69. https://doi.org/10.7454/mssh.v21i2.3501

Rotundo, M., \& Sackett, P. R. (2002). The relative importance of task, citizenship, and counterproductive performance to global ratings of job performance: A policycapturing approach. Journal of Applied Psychology, 87(1), 66-80. https://doi.org/10.1037/0021-9010.87.1.66

Sahertian, P. (2010). Perilaku kepemimpinan berorientasi hubungan dan tugas sebagai anteseden komitmen organisasional, self-efficacy dan organizational citizenship behavior (OCB). Jurnal Manajemen dan Wirausaha, 12(2), 156-169.

Schwartz, S. H. (2017). Values and behavior: Taking a cross culture perpective. Personality $\begin{array}{llll}\text { and Social Psychology } & \text { Bulletin, 29(10), }\end{array}$ https://doi.org/10.1177/0146167203254602

Smith, C. A., Organ, D. W., \& Near, J. P. (1983). Organizational citizenship behavior: Its nature and antecedents. Journal of Applied Psychology, 68(4), 653-663. https://doi.org/10.1037/0021-9010.68.4.653

Spector, P. E. (2006). Method variance in organizational research: Truth or urban legend? Organizational Research Methods, 9(2), 221-232. https://doi.org/10.1177/1094428105284955

Spector, P. E., Bauer, J. A., \& Fox, S. (2010). Measurement artifacts in the assessment of counterproductive work behavior and organizational citizenship behavior: Do we know what we think we know? Journal of Applied Psychology, 95(4), 781-790. https://doi.org/10.1037/a0019477

Susanto, E. (2015). Pengaruh kepemimpinan transformasional terhadap organizational citizenship behavior (OCB) melalui pemberdayaan karyawan dari beberapa fakultas di Universitas Trisakti Jakarta. Jurnal Manajemen dan Pemasaran Jasa, 8(1), 95-112. https://doi.org/10.25105/jmpj.v8i1.1403

Tjahjono, H. K., Prasetyo, F., \& Palupi, M. (2018). Kepemimpinan transformasional pada organizational citizenship behavior dan komitmen afektif. Jurnal Manajemen dan Pemasaran Jasa, 11(2), 217-232. https://doi.org/10.25105/jmpj.v11i2.2771

Van Dyne, L., \& LePine, J. A. (1998). Helping and voice extra-role behaviors: evidence of construct and predictive validity. Academy of Management Journal, 41(1), 108-119. https://doi.org/10.2307/256902 
Walumbwa, F. O., Hartnell, C. A., \& Oke, A. (2010). Servant leadership, procedural justice climate, service climate, employee attitudes, and organizational citizenship behavior: A cross-level Investigation. Journal of Applied Psychology, 95(3), 517-529. https://doi.org/10.1037/a0018867

Wijayanto, B. R., \& Kismono, G. (2004). The effect of job embeddedness on organizational citizenship behavior: The mediating role of sense of responsibility. Gadjah Mada International Journal of Business, 6(3), 335-354. https://doi.org/10.22146/gamaijb.5554

Williams, L. J., \& Anderson, S. E. (1991). Job satisfaction and organizational commitment as predictors of organizational citizenship and in-role behaviors. Journal of Management, 17(3), 601-617. https://doi.org/10.1177/014920639101700305 